\title{
Senhor Babadook, Vincent e o horror
}

\section{materno: intertextos}

\author{
Laura Canepa ${ }^{1}$
}




\section{Resumo}

Este trabalho se propõe a analisar a relação de intertextualidade entre os filmes Senhor Babadook, de Jennifer Kent (The Babadook, Austrália, 2014) e Vincent, de Tim Burton (EUA, 1982). Tal relação será examinada a partir da ideia de uma reconstrução da narrativa do filme de Burton pelo de Kent por um procedimento de inversão do ponto de vista. Tal procedimento permite a Senhor Babadook explorar um tema caro às histórias de horror que está apenas sugerido em Vincent: o horror materno ("maternal horror", ARNOLD, 2013), conceito inspirado nas ideias de Julia Kristeva (1982) e Barbara Creed (1993).

Palavras-chave

Cinema, intertextualidade, horror, horror maternal, horror infantil.

\section{Abstract}

This paper investigates the intertextuality between the films The Babadook, by Jennifer Kent (Australia, 2014), and Vincent, by Tim Burton (USA, 1982). The connection between these two films will be examined from the idea of a narrative reconstruction of the Burton's film by Kent's by a procedure of reverse perspective. This procedure allows The Babadook to explore an important theme in horror stories that is only suggested in Vincent: the maternal horror (ARNOLD, 2013), a concept inspired by the authors as Julia Kristeva (1982) and Barbara Creed (1993).

\section{Keywords}

Cinema, intertextuality, horror, maternal horror. 

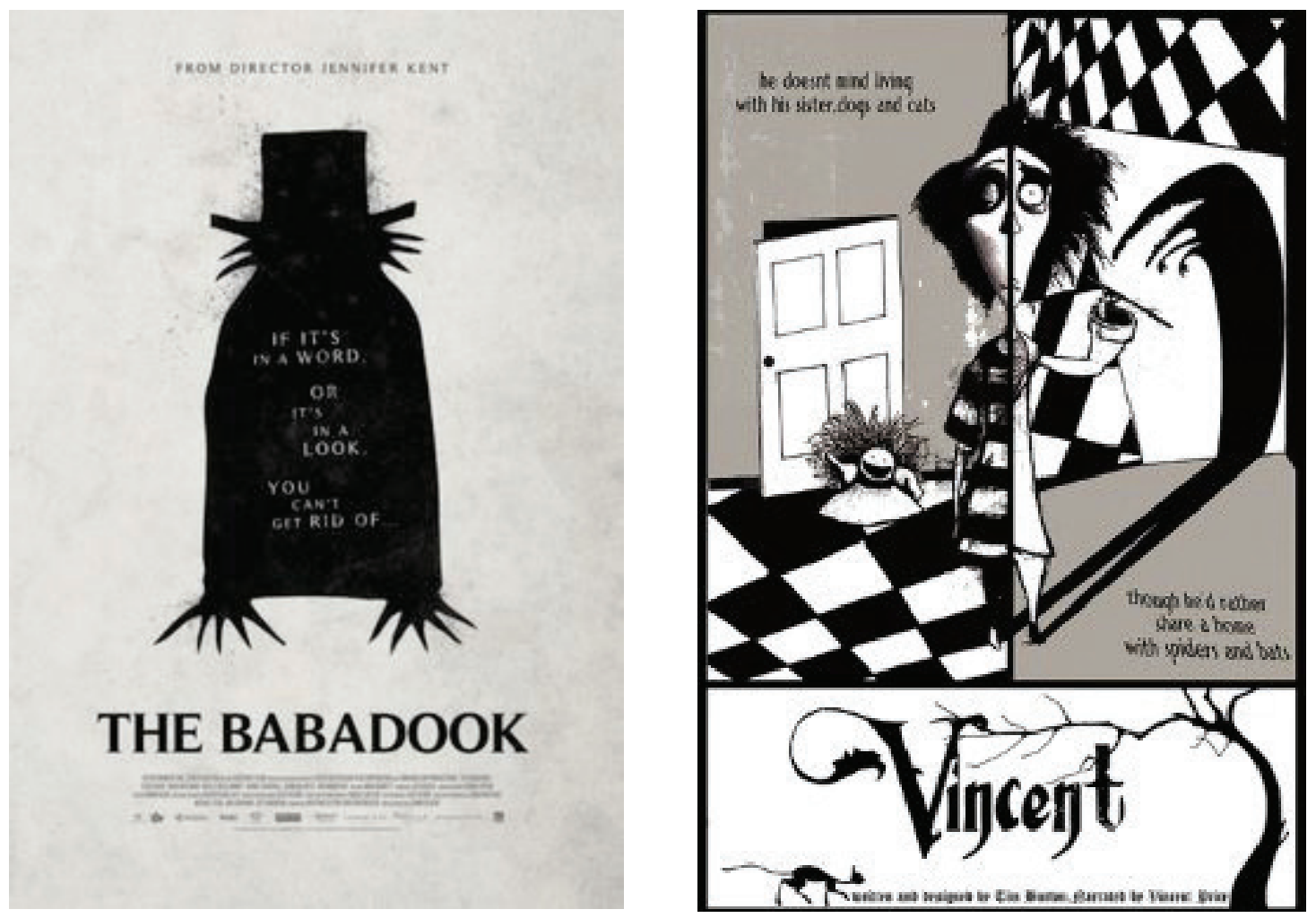

Figuras 1 e 2: Cartazes de The Babadook (2014) e de Vincent (1982)

\section{Preâmbulo: sobre a inclusão deste texto no dossiê Eduardo Peñuela}

As aulas do professor Eduardo Peñuela fizeram parte de meus primeiros contatos sistemáticos com os estudos acadêmicos de cinema, na Escola de Comunicações e Artes da USP (ECA-USP), em 1999. Na ocasião, eu ingressara no mestrado para pesquisar aspectos do expressionismo cinematográfico em filmes do cineasta estadunidense Tim Burton².

Minha pesquisa estava, em princípio, distante do campo de interesse do professor. Primeiro, porque tratava de uma vanguarda (a expressionista) que tinha diferenças significativas daquela que sempre interessara a ele: a surrealista. Segundo, porque abordava grandes produções de Hollywood - que, como se 
sabe, são em geral avessas ao tipo de construção poética de que Peñuela tratava em suas aulas. Isso, claro, não me impediu de acompanhar seus cursos ao longo de vários semestres, mas sempre constituiu um desafio quando chegava a hora de elaborar os trabalhos finais.

Quando fui desafiada, na condição de ex-aluna, a participar deste Dossiê, vi-me novamente diante da mesma dúvida: sobre o que escrever? Lembrei-me, então, do primeiro trabalho que fiz para uma de suas disciplinas. Tratava-se de uma análise dos aspectos expressionistas do filme Vincent (Tim Burton, 1982). O curta de animação contava a história de um menino obcecado por histórias de horror que, incompreendido pela mãe, transformava o espaço da casa deles em projeção de seus pesadelos.

Mas não faria sentido resgatar esse trabalho, já incorporado à minha dissertação há mais de dez anos. Passei a esperar, então, que o "acaso objetivo" acalentado pelos surrealistas viesse em meu socorro. Finalmente, em dezembro de 2014, assisti ao filme de horror australiano Senhor Babadook (The Babadook, Jenniffer Kent, 2014), que me remeteu diretamente a Vincent - só que, desta vez, a história estava sendo contada pelo ponto de vista da mãe. Essa mudança de perspectiva (e tudo que a acompanha) podia inspirar a continuidade e a problematização das reflexões iniciadas em 1999. Assim, comecei a elaborar minha contribuição para este Dossiê, recuperando alguns aspectos do aprendizado sobre a poética do cinema que dizem respeito à intertextualidade e a alguns conceitos extraídos da psicanálise.

\section{Abram as portas para o Babadook}

Filme-sensação do XX Festival Internacional de Cinema Fantástico de Gerardmer em 2014, Senhor Babadook, longa-metragem australiano escrito e dirigido por Jennifer Kent, tornou-se um dos filmes de horror mais celebrados do ano pela crítica internacional ${ }^{3}$. Trata-se do primeiro longa-metragem da diretora, 
por sua vez, baseado em seu curta de estreia, Monster, de 2005. A história trata da psicose progressiva da enfermeira Amelia (Essie Davis), que é viúva e precisa lidar com os problemas do filho Samuel (Noah Wiseman), de sete anos de idade, cujo comportamento violento tem origem em monstruosas visões. O tormento do menino é resultado do sentimento de culpa pela morte do pai em um acidente de carro a caminho da maternidade, no dia de seu nascimento. As crises de Samuel obrigam Amelia a lidar com a rejeição social, o que se complica quando as ameaças imaginadas pelo filho se materializam e passam a persegui-la também.

O filme foi comparado a obras clássicas do horror cinematográfico como 0 exorcista (William Friedkin, EUA, 1973) e Carrie - a estranha (Brian De Palma, EUA, 1976), que trazem mães desafiadas pelo horror sobrenatural que ameaça suas filhas ${ }^{4}$. Alguns críticos também relacionaram Senhor Babadook às obras de Roman Polanski, Repulsa ao Sexo (França, 1965), que trata da psicose de uma mulher hostil ao sexo oposto, e O bebê de Rosemary (EUA, 1968)5, sobre uma mulher grávida que acredita ter sido inseminada em ritual demoníaco. Em Senhor Babadook, porém, os problemas enfrentados por mãe e filho têm aspectos mais cotidianos e domésticos do que nesses filmes. No longa de Kent, as questões do dia-a-dia - o trabalho, a escola, a alimentação, as relações familiares, a presença das autoridades - nunca desaparecem do horizonte de preocupação das personagens. Além disso, nessa obra, diferentemente das anteriores, o melodrama familiar tem preponderância sobre o horror.

A trama, desenvolvida linearmente, tem início com a apresentação da rotina ao mesmo tempo triste e resignada de Amelia. Ela tem pesadelos recorrentes com o acidente de carro que vitimou o marido; veste-se sempre com o mesmo uniforme de enfermeira; é acordada todas as noites pelo filho para certificá-lo de que não há monstros em seu quarto; negocia diariamente com ele para que não leve à escola as armas artesanais que fabrica no porão da casa; assiste com 
indiferença aos truques de mágica que o menino treina de forma obsessiva; cumpre seu trabalho num hospital onde cuida de pessoas idosas; passa alguns momentos do dia com sua irmã e sobrinha, mas percebe que ambas estão cada vez mais intolerantes às crises de Samuel. Nas horas vagas, fica prostrada em frente à TV, na companhia do cãozinho Bugsy, assistindo randomicamente à programação de diversos canais de notícias e a filmes fantásticos (de curtas do mágico francês Georges Meliès a longas de horror de Mario Bava). Nos poucos momentos solitários em que Amelia toma iniciativas dirigidas ao prazer (como flertar, masturbar-se ou comer um sorvete), as demandas assustadoras de Samuel a interrompem. Ela está só, exausta e dorme cada vez menos.

Certa noite surge na estante do quarto de Samuel um exemplar misterioso. O livro parece editado artesanalmente e traz desenhos em preto e branco inspirados nas construções labirínticas de escritores/ilustradores como Dr. Seuss e Edward Gorey, autores de clássicos da literatura infantil anglo-americana do século XX como The cat in the hat e The gashlycrumb tinies. Os desenhos surgem em alto relevo e ilustram um poema macabro escrito em rimas simples também semelhantes às desses autores estadunidenses. É chegado o Babadook:

A rumbling sound, than three sharp knocks you better run, or he'll hold you in his locks. ba-ba-ba-dook-dook-dook... Your closet opens and your honestly hopin' that he won't hear a sound but that's when you know that he's around. The book close, you have an itch under your nose and that's just how the story goes.

So close your eyes and count to ten better hope you don't wake up again.

'Cause if it's in a word, or if it's in a book you can't get rid of the Babadook ....you'll see him if you look. ${ }^{6}$

6 Um estrondo,/Três batidas fortes/ é melhor você correr,/ ou ele vai te segurar em seus cabelos./ Ba- ba- ba- dook dook - dook.../Quando seu armário abre e você deseja não ouvir nenhum som / É quando você sabe que ele está por perto./O livro fecha e você tem uma coceira debaixo do seu nariz/E é assim que a história continua./Então feche seus olhos e conte até dez./Melhor não acordar novamente./Porque estando ele numa palavra ou em um livro /Você não poderá se livrar do Babadook/E para vê-lo basta você olhar. 
O monstro do livro usa a capa e o chapéu do figurino de Lon Chaney no clássico perdido de vampiros London After Midnight7 (Tod Browning, EUA, 1927), mas sua indumentária remete igualmente ao mágico televisivo imitado por Samuel, e ainda às peças de roupas do pai preservadas no quarto da mãe. Como uma espécie de metáfora em abismo dos tormentos de Samuel, Babadook (Figura 1) é assustador: suas unhas são longas, seus dentes são afiados, seu semblante é deformado e sua intenção invadir o corpo de suas vítimas, tirando-Ihes a personalidade.

Ao término da leitura, Samuel está em pânico. Sua mãe esconde o livro, mas este reaparecerá várias vezes, mesmo após ter sido incinerado por ela na churrasqueira. Ela pede ao filho que não mencione Babadook, para não despertar mais desconfianças sobre sua sanidade. Mas o menino não se contém. Ele acaba ferindo um colega com sua pistola de pregos feita para eliminar Babadook. É expulso da escola, o que obriga sua mãe a ausentar-se do trabalho por vários dias. Ele também agride a prima em sua festa de aniversário, azedando de vez as relações familiares.

Sozinha o dia inteiro com o filho, a mãe começa a se desestruturar. Em diálogos estratégicos diluídos pela narrativa, ficamos sabendo que, depois da morte do marido, Amelia teria deixado a profissão de escritora de textos para crianças, e que uma depressão não tratada a acompanha desde então. Desesperada por descanso, ela pede ajuda a um pediatra, que dá um calmante de uso contínuo a Samuel. O medicamento funciona para diminuir a agitação do menino, mas sua quietude evidencia a apatia e a tristeza da mãe. E então o monstro Babadook passa a perseguir Amelia.

Progressivamente, Samuel (e também os espectadores) vão perdendo a confiança nela. A casa em que vivem se transforma em prisão obscura a partir do

7 Chamado no Brasil de Vampiros da meia-noite, o filme mudo produzido pela empresa Metro Goldwin Mayer e estrelado pelo astro do horror do cinema mudo Lon Chaney teve sua última cópia perdida num incêndio em 1965 , sendo conhecido hoje pelo roteiro (inspirado no conto The hypnotist, de Tod Browning) e nas imagens fotográficas preservadas. O culto à memória desse filme transformou-se em verdadeira "caça ao tesouro" entre historiadores de cinema e fãs de horror. Há uma cópia disponível com montagem feita a partir do roteiro e das imagens still. 
olhar poderoso de mãe. Ela se torna ofensiva, impaciente e violenta. Num de seus sonhos, o monstro avisa a Amelia: "I'll make you a bet. The more you deny, the stronger I get. The Babadook is growing right under your skin" ${ }^{8 \prime}$. Assim, Babadook não se apresenta mais apenas como projeção da imaginação de Samuel, mas principalmente - do luto não superado e do ressentimento da mãe.

Sob a influência do monstro, Amelia estrangula Bugsy. Samuel, então, decide parar de tomar os remédios, tentando assumir as rédeas da situação. Por telefone, ele pede ajuda à vizinha idosa, que parece ser a única a preservar a afeição por eles, mas a mãe não o deixa concluir a conversa. Babadook aparece para Amelia na forma de seu marido morto, e exige o sacrifício do filho. Mas, quando está prestes a alcançar seu objetivo, o garoto consegue impedilo, usando suas armas artesanais contra a própria mãe, e expulsando enfim o monstro de seu corpo. Ela recobra a consciência e protege o garoto do último ataque de Babadook. Com suas últimas forças, grita para o monstro para que não se aproxime mais do seu filho.

Uma breve passagem de tempo mostra Amelia e Samuel comemorando, pela primeira vez, o aniversário dele, com doces e números de mágica. A vizinha faz uma visita aos dois. A mãe está novamente vestida com seu uniforme de enfermeira. Ela e Samuel parecem felizes. O menino interrompe a festa para buscar larvas e minhocas no jardim. Em seguida, elas são entregues à mãe, que as leva ao porão para alimentar o Babadook - agora aprisionado junto aos objetos do pai. Fim.

\section{Vincent / Samuel}

Embora se esteja tratando aqui de filmes muito diferentes - um longametragem a cores filmado em live-action (SenhorBabadook); um curta-metragem em preto e branco feito em stop-motion (Vincent) - as correspondências entre as obras de Kent e de Burton são notáveis. 
O filme de estreia de Burton, realizado em 1982, foi um experimento conduzido nos estúdios Disney, que então enfrentavam a maior crise de sua história. O curta, considerado impróprio para crianças pequenas, não chegou a ser exibido comercialmente junto a longas do estúdio. A obra só ficaria conhecida anos depois da consagração de seu diretor em filmes comerciais de longa-metragem como Os fantasmas se divertem (Bettlejuice, 1988) e Batman o filme (Batman, 1989).

Vincent narra aventuras domésticas do tímido Vincent, de sete anos de idade, que, em seus devaneios, imagina ser o astro do cinema de horror Vincent Price. Ele acaba sendo levado ao esgotamento psicológico pela dificuldade de dividir suas fantasias com as mulheres que o cercam - a irmã pequena, sua tia e, principalmente, sua mãe. Seu cão de estimação, Abercrombie, é a única companhia verdadeira de Vincent. Ao lado dele, desenvolve experiências científicas e atravessa castelos góticos imaginários inspirados em filmes fantásticos dos anos 1920, como London after midnight e O gabinete do dr. Caligari (Robert Wiene, 1919). Tudo se passa no espaço doméstico, mas a locução do próprio Vincent Price remete desde o início às histórias clássicas de horror. Sua voz é a única que ouviremos ao longo do filme, assumindo as falas das personagens, como quem lê a história para uma criança.

Logo de início, somos apresentados à personagem principal por meio de um poema em rimas infantis ao estilo de Dr. Seuss: "Vincent Malloy is seven years old/ He's always polite and does what he's told/ For a boy his age, he is considered nice / But he wants to be just like Vincent Price" ${ }^{\prime \prime}$. O filme tornará visível a identificação do menino com o ator-personagem promovendo uma série de transições entre Vincent-como-ele-mesmo e Vincent-como-Vincent-Price (Figura 2). Cada uma dessas transições ocorre em continuidade temporal, mas com alterações espaciais que marcam a projeção da imaginação de Vincent sobre o mundo que o cerca. 
A hostilidade do garoto direcionada às figuras femininas - inspirada, em parte, por filmes de horror estrelados por Price e homenageados no curta (como Museu de cera, 1953; O solar maldito, de 1960) - é revelada ao espectador, num primeiro momento, quando ele recebe a visita de uma tia. De costas para uma mulher gorda que afaga seus cabelos, Vincent puxa uma corrente imaginária, e ela é mergulhada em um enorme caldeirão de cera. A falta de preocupação ou remorso do menino é evidente. Mas as coisas se complicam para ele durante a leitura de seu autor favorito (Edgar Allan Poe), pois Vincent descobre que sua "amada esposa" fora enterrada viva no quintal da casa ${ }^{10}$. Desesperado, ele corre até a sepultura para resgatá-la. Porém, subitamente, a cova aberta pelo garoto em plena madrugada se revela um (agora destruído) jardim florido sob o sol mais especificamente, aquele que abriga as flores cultivadas com todo o cuidado por sua mãe.

E ela não gosta nada da brincadeira. Vincent é colocado de castigo, convencido de que foi banido pela mãe para sempre. Na parede do seu quarto, um enorme desenho de sua "esposa" confunde-se com a figura da mãe - de quem, como em muitos desenhos animados, só podemos ver até a cintura. A substituição de uma (a mãe) pela outra (a do retrato) é clara. Pouco depois, ela volta a interromper a fantasia do filho, sugerindo que ele saia para brincar. Mas a comunicação entre os dois fica cada vez mais difícil:

Vincent tried to talk, but he just couldn't speak, The years of isolation had made him quite weak. So he took out some paper, and scrawled with a pen: "I am possessed by this house, and can never leave it again"11.

A mãe perde a paciência. Com o dedo apontado para Vincent, argumenta

10 Provável referência ao conto $A$ Queda da Casa de Usher, de Egdar Allan Poe, que serviu de inspiração para o filme o Solar Maldito, estrelado por Price em 1960. Esse filme deu origem ao ciclo de adaptações de Poe para o cinema, capitaneado pelo diretor/produtor Roger Corman. 
You're not possessed, and you're not almost dead.

These games that you play are all in your head. You're not Vincent Price, you're Vincent Malloy You're not tormented or insane, you're just a young boy. You're seven years old, and you're my son, I want you to get outside and have some real fun ${ }^{12}$.

Apavorado, Vincent retorna à escuridão de seu quarto, cada vez mais distante da realidade. As paredes se transformam em telas onde revê todos os seus horrores: a amada morta, o jardim destruído, a tia derretida. Mãos esqueléticas saem pelas paredes tentando capturá-lo, e ele tenta correr até a porta, mas cai, exausto, antes de conseguir sair. Price conclui a narração, citando O corvo, de Poe: "His voice was soft and very slow,/ as he quoted The Raven from Edgar Allen Poe. /'And my soul from out that shadow floating on the floor/ Shall be lifted - Nevermore!"' 13

Deitado no fundo do quarto, com uma luz fraca apenas sobre seu corpo imóvel, Vincent parece ter morrido - ou apenas desistido. Não importa: a câmera toma distância dele até que seu corpo se torne um pequeno ponto embaixo no quadro, subjugado pela escuridão. Ainda que seja difícil precisar se estamos presenciando apenas mais uma de suas brincadeiras, Vincent parece dividir com o protagonista de 0 corvo (o estudante que chora a morte de sua amada Lenore) aquilo que os poetas românticos como Poe descreveriam como a paixão humana pela autoflagelação, uma espécie de luxúria do sofrimento. Em sua autoindulgência, Vincent, isolado e incompreendido como os heróis românticos, é o primeiro dos muitos sujeitos deslocados que Tim Burton descreveria em seus filmes seguintes. 
Comparando-se esse pequeno filme a Senhor Babadook, várias observações são possíveis. Primeiro, pode-se aproximar os personagens Vincent e Samuel. Ambos têm a mesma idade e são atormentados por pensamentos violentos inspirados em histórias encontradas na TV e nos livros. As semelhanças físicas entre os dois também são notórias: cabelos escuros, semblante pálido e olhar exageradamente assustado. Suas experiências de vida são marcadas igualmente pela ausência do pai (tematizada em Babadook e apenas sugerida em Vincent), compensada pela adoção de figuras paternas idealizadas e vinculadas ao mundo da fantasia e do oculto: um mágico em Babadook; um astro de filmes de terror, em Vincent.

Semelhanças também podem ser encontradas no repertório cinéfilo, gráfico e literário mobilizado para a construção das duas narrativas, como a inspiração em Dr. Seuss e Edward Gorey, e também num tipo de cinefilia de horror que compartilha citações de certas obras, como London after midnight. Apesar das enormes diferenças entre as produções, pode-se perceber, ainda, em ambas, o investimento na transformação visual de casas suburbanas em espaços fantásticos e mal assombrados, deformados pela imaginação das personagens, em procedimento de matriz expressionista muito caro aos filmes de horror.

Mas, para a análise aqui proposta, interessa refletir sobre uma personagem que, secundária em Vincent, torna-se central em Senhor Babadook: a mãe. Já foi dito anteriormente que tanto Samuel, quanto Vincent, são garotos cercados de mulheres com quem têm dificuldade de se comunicar - principalmente suas mães. Estas resistem às fantasias dos filhos de todas as maneiras, e chegam mesmo a rejeitá-los quando tais fantasias "passam a ato" e interferem em seus momentos ou objetos de prazer (o jardim, o sorvete, a masturbação). No entanto, se o filme de Burton adota a perspectiva autoindulgente do garoto, para Kent, ao contrário, serão as dificuldades da mãe que conduzirão a narrativa. Nesse sentido, podem ser úteis as reflexões de diversos autores sobre o horror materno para sugerir a existência de uma relação entre esses dois filmes. 


\section{Horror materno}

A maternidade é um tema frequente em histórias de horror, principalmente naquelas contadas pelo cinema nos últimos 65 anos. David Greven, por exemplo, no ensaio Representations of femininity in American genre cinema (2011), destaca que os popularíssimos "filmes de mulher" (woman's films) dos anos 1930 e dos 1950, que eram em grande parte dedicados à experiência feminina da maternidade, foram incorporados com sucesso pelo cinema de horror moderno a partir dos anos 1960:

Eu defendo que o supostamente falecido gênero do filme de mulher toma uma nova forma no moderno filme de horror, que repropôs o melodrama e se expandiu a partir do precedente de Psicose, de Hitchcock, em 1960. Esse horror moderno pode ser dividido em duas categorias: o horror edípico, focado nos conflitos entre pais e filhos, e o perséfono, focado nos problemas entre mães e filhos, quase sempre filhas ( $O$ Exorcista, Carrie, a série Alien), mas por vezes também filhos, usualmente em filmes de tema queer (a série Sexta-Feira 13, 0 silêncio dos inocentes etc) (GREVEN, 2011, p. 83). ${ }^{14}$

O tipo de horror perséfono descrito por Greven - isto é, naquele focado nos conflitos entre mães e filhos - pode ser encontrado nas histórias descritas em Senhor Babadook e Vincent. O autor estabelece em Psicose (1960) a origem da popularidade desse tipo de história no cinema de horror, assumindo a periodização feita por vários historiadores, que apontam nesse filme o nascimento do horror moderno cinematográfico. Robin Wood, por exemplo, em seu estudo seminal sobre o horror hollywoodiano (1979, p. 30), mostrou que Hitchcock, em Psicose, superou a tradição de origem europeia, afastando o horror dos castelos medievais e dos laboratórios de cientistas loucos, adaptando os modelos góticos para um tipo de ambiente burguês e familiar. 
A partir de Psicose, as relações familiares foram ganhando cada vez mais espaço no cinema de horror, e assim o gênero passou a receber maior atenção dos estudos ligados à Psicanálise, pois alia três aspectos atraentes para esse tipo de abordagem: a representação da ansiedade surgida a partir de eventos que escapam à normalidade; a construção de um tipo específico de prazer visual ligado aos processos inconscientes; a frequente apresentação da família nuclear em situações extremas e irreconciliáveis.

A discussão se aprofundou a partir dos anos 1970 com a contribuição dos estudos feministas de matriz psicanalítica, que transformaram o gênero em objeto de disputa num debate intenso ao longo das últimas décadas. Muitos dos estudos feministas dedicados ao cinema de horror deram atenção às histórias de monstros do sexo masculino que atacam mulheres. Por exemplo, em trabalhos de Linda Williams (1996), Ann Kaplan (1993) e Carol Clover (1993) - baseados, por sua vez, nas formulações de Laura Mulvey (1983) ${ }^{15}$ - os filmes de horror foram apresentados como resultado da hostilidade patriarcal pelo reconhecimento da diferença sexual. A violência contra as mulheres nos filmes de horror teria, para essas autoras, a função de garantir o controle masculino sobre a sexualidade feminina.

Por outro lado, para uma autora como Barbara Creed (1993) é possível relacionar também de outro modo o gênero (narrativo) do horror ao gênero (sexual) feminino. Inspirada pelas ideias de Julia Kristeva (1982), Creed desenvolveu um estudo sobre o cinema de horror em que aborda as representações nas telas do que chama de monstruous feminine (monstruoso feminino). A autora observa que monstros femininos estão presentes em diversas culturas há milênios. Ela cita como exemplos figuras míticas como as sereias, as bruxas, as vampiras, as mulheres com vaginas dentadas e mesmo a Medusa - esta última vinculada pelo próprio Freud à imagem dos genitais femininos (1993, p. 01-02). Reconhecendo a importância e a recorrência de tais figuras, buscou examinar a potência dos monstros femininos para atrair e apavorar as audiências, enfatizando a sua diferença em relação aos monstros masculinos. 
Segundo Creed descreve (citando exemplos de autores como Gerard Lénne, Steve Neale e David Hogan), os monstros femininos são em geral tratados pelos teóricos como monstros masculinos castrados. No entanto, para ela, o horror relativo à castração não precisa necessariamente ser devido ao fato de que as mulheres sejam castradas, mas exatamente ao fato de que elas não o são - e nesse sentido, tornaram-se monstruosas para uma cultura falocêntrica (1993, p. 6). Assim, Creed mostra que a mulher pode, em certo sentido, ser compreendida como o próprio monstro da ficção de horror, pois, ao revelar a diferença sexual, ela é capaz de gerar, por sua própria existência, sentimentos de ansiedade e abjeção.

O trabalho de Creed foi inspirado no ensaio de Kristeva Pouvoirs de I'horreur ${ }^{16}$, publicado pela primeira vez em 1980. Nesse trabalho, a autora alega que a abjeção (operação psíquica em que a identidade subjetiva se constitui pela exclusão das ameaças às fronteiras do sujeito) tem origem não na castração como defendem as principais correntes da psicanálise adotadas pelos estudos feministas - mas sim na dependência originária do corpo materno (1982, p. 06). Para Kristeva, a mãe dominadora, presente na vida do filho tanto na fase pré-simbólica quanto na fase posterior - sendo capaz, portanto, de atravessar esses dois estágios da vida psíquica -, estaria na origem da abjeção. A presença dela nos faz recordar não apenas de nossa origem de total dependência, mas também de nossa ligação biológica, remetendo-nos a ideias perturbadoras como as de concepção, parto e amamentação (1982, p. 13-14). Como observa Sarah Arnold (2013, p. 06), para Kristeva, a mãe é a lembrança de um momento em que a criança nada mais era do que um pedaço dela, indissociada de outros órgãos dentro de seu corpo. Não por acaso, os corpos devorados, os ruídos primitivos (como grunhidos e gemidos) e os fluidos corporais são presenças constantes nas histórias de horror. 
Em 2013, Sarah Arnold empreendeu um exame de filmes de horror protagonizados por figuras maternas em Maternal horror film: melodrama and motherhood, trabalho no qual buscou compreender os vínculos dos filmes de horror com outro gênero: o melodrama. Segundo ela, no âmbito das análises psicanalíticas de obras vinculadas tanto ao horror quanto ao melodrama, abundam conceitos psicanalíticos. Porém, destaca a autora, há uma tendência a se aplicar ao horror conceitos como os de retorno do reprimido e estranho e, ao melodrama, conceitos como complexo de édipo e masoquismo. No entanto, para Arnold, a interseção entre os gêneros é fundamental para a compreensão de um tema recorrente em ambos - a maternidade - pelo fato deles recorrerem, com frequência, à ideia do sacrifício materno (2013, p. 5).

Ela inicia suas reflexões retomando a centralidade do filme Psicose, e lembrando que a figura da mãe nesse filme é objeto ao mesmo tempo de fascinação e repulsa (ARNOLD, 2013, p. 1). Porém, alerta a autora, não se pode generalizar, a partir dele, a ideia de que todas as mulheres nos filmes de horror representem a função materna ou mesmo o sexo feminino. Trata-se, então, de buscar as especificidades de um tipo particular de personagem. Para Arnold (2013, p. 23), há duas representações básicas da função materna nos filmes de horror, que podem ser percebidas numa oposição entre o autossacrifício e o egoísmo: a "Mãe Boa" (the good mother), que é abnegada e sacrifica seus desejos em nome dos filhos; a "Mãe Má" (the bad mother), que é sádica, exigente, ciumenta e quer ter controle sobre a própria vida e dos que a cercam, não raro sendo considerada "fálica" em análises das obras que protagonizam. O mais comum no horror materno, segundo Arnold, é que a mãe seja a encarnação da abjeção e da monstruosidade, tendendo a tomar conta da narrativa e devendo, por isso, ser punida (ARNOLD, 2013, p. 27).

Inúmeros exemplos podem ser buscados para ilustrar os tipos de mães descritos por ela. A autora cita, entre vários outros, a "mãe boa" que protagoniza o filme japonês O chamado (Ringu, Hideo Nakata, 1998) e a "mãe má" que comanda o horror em Os filhos do medo (The brood, David Cronenberg, 1979). A 
partir dessa dicotomia, Arnold busca comparar o papel das mães nas narrativas melodramáticas com a narrativa da maternidade que foi construída pela própria psicanálise. Para isso, ela assume como premissa que as narrativas de horror derivadas do modelo de Psicose incorporam conceitos psicanalíticos em sua própria construção. Segundo ela afirma, citando Noel Carroll, "a psicanálise é certamente relevante, mesmo pertinente, à análise de muitos filmes de horror, porque muitos filmes de horror pressupõem, explícita ou implicitamente, os conceitos e o imaginário psicanalíticos"17 (CARROL, apud ARNOLD, 2013, p. 3).

Segundo a autora, tanto o melodrama quanto a teoria psicanalítica reproduzem e racionalizam, cada um a seu modo, o modelo patriarcal, fornecendo às mulheres uma espécie de receita sobre o modo "correto" de cumprir seu papel - que implica, quase sempre, na maternidade e no sacrifício da própria subjetividade em favor dos filhos. Por isso, tanto na psicanálise quanto no melodrama, o papel da mãe não apenas é fixo e limitado, como deve seguir uma progressão rígida conforme o gênero e a idade da criança (2013, p. 6).

Arnold observa que, para a psicanálise, a figura do pai encarna o superego, sendo responsável pela transição do filho para a Cultura, enquanto a mãe fica ligada aos estágios mais primitivos e pré-conscientes, sendo marcada sobretudo pela passividade e pela falta: na fase pré-edipica, ela é apenas um objeto de desejo; na fase posterior, ela traz a castração simbólica (2013, p. 07). Ela destaca que Jacques Lacan, ao retomar o pensamento de Freud, manterá essa noção, atribuindo à criança o desejo de ser o falo que falta à mãe. Assim, a mãe é, para o filho, ao mesmo tempo plenitude (porque o gera) e falta (por não ter o falo) (2013, p. 9). Porém, o lapso evidente, conforme observa Arnold, é o fato de que subjetividade da mãe está pouco refletida nessas teorias. Trata-se de uma falta evidente, nessa perspectiva (2013, p. 10). A narrativa proposta pela 
psicanálise, assim, se aproxima, a seu modo, da ideia de sacrifício materno tão cara ao melodrama: o filho é a Lei, e à mãe basta cumprir seu papel.

A partir desse quadro, a autora conclui que a maternidade, ao mesmo tempo em que é um dos poucos espaços de poder dados à mulher dentro da lógica patriarcal, só permite o exercício do poder dentro de limites muito estritos. A mãe que tentar ultrapassar o domínio que lhe é permitido poderá se tornar figura abjeta, monstruosa (ARNOLD, 2013, p. 18). No caso de Senhor Babadook, realizado pouco depois do lançamento do livro de Arnold, pode-se sugerir uma "ilustração" dessa relação entre o horror materno e o melodrama. No filme de Kent, a mãe compassiva se transforma em figura abjeta, capaz de conjurar um monstro cujo poder destrutivo incorpora sua inconformidade ao papel de mulher sacrificada e assexuada que seu filho e sua solidão Ihe impõem.

\section{Senhor Babadook, Vincent e o horror materno: breves conclusões}

As semelhanças entre Senhor Babadook e Vincent permitem sugerir uma relação intertextual, mas suas diferenças talvez sejam mais esclarecedoras dessa relação. E elas se encontram, sobretudo, no espaço dado à subjetividade das mães.

Vincent apresenta um menino que substitui uma figura paterna ausente por um personagem de filmes de horror, e, imbuído dessa personalidade, realiza uma série de fantasias violentas que têm por objeto figuras femininas adultas, principalmente sua mãe poderosa e inatingível. Seu comportamento articula ansiedades masculinas que atribuem às mulheres qualidades que as tornam objetos de desejo e ao mesmo tempo de repulsa. Já em Senhor Babadook, a ansiedade do personagem masculino passa a ser compartilhada de modo igualmente horrífico com a mãe. Ela, ao perceber o filho como um ser separado e diferente dela, mas ao mesmo tempo frágil e dependente, vê-se horrorizada diante da própria cria, alimentando um ciclo vicioso de abjeção e desejo de morte.

Nos dois filmes, a ausência do pai se faz notar, mas, em Babadook, o pai é constantemente lembrado por objetos e substituições simbólicas, sugerindo uma espécie de "presença" constante dessa ausência. Ele está presente, e ao mesmo 
tempo não está, constituindo-se como uma falta. Sua morte por decapitação pouco antes do nascimento do filho também remete à noção psicanalítica de castração. Mas seu filho, ainda que aterrorizado, não se apresenta como fonte demoníaca de afastamento do par amoroso. Seu papel nesse processo está dado como acidental. O menino não parece amaldiçoado, nem possuído. Assim, a chegada do horror (Babadook) será provocada por outras vias: Amelia, a mãe, será a verdadeira força capaz de produzi-lo.

Em Senhor Babadook, a ideia da mãe monstruosa e abjeta, que deseja exercer o poder de vida e morte sobre o filho, está evidente, ao mesmo tempo em que estão evidentes os limites de sua experiência como mãe autossacrificada e compassiva. Aqui, a metáfora melodramática que descreve a maternidade como "ter o coração fora do corpo"18 se apresenta com um novo significado - agora horrífico. O coração que vive fora do corpo de Amelia não é seu filho (Samuel), mas uma entidade imaginária masculina (Babadook) que reúne seu sofrimento, seu ressentimento e seu desejo de recusar os sacrifícios que a maternidade lhe exige.

A roteirista/diretora australiana, no entanto, parece querer salvar mãe e filho de uma relação fadada à neurose e à morte. Trata-se de uma solução possível apenas pelo amor que eles nutrem um pelo outro, resultando num tipo de conclusão melodramática diferente das que se encontram em filmes comparados a Senhor Babadook (como Carrie - a estranha, Repulsa ao sexo e mesmo Vincent). No filme de Kent, tem-se um arranjo frágil, periclitante, mas que permite a sobrevivência das personagens por meio do reconhecimento e da aceitação de suas fantasias mórbidas, incorporadas ao mobiliário cotidiano como entidade necessária para a continuação - sempre provisória - da vida. 


\section{Referências}

ARNOLD, S. Maternal horror film: melodrama and motherhood. New York: Palgrave Macmillan, 2013.

CLOVER, C. Men, women, and chain saws: gender in modern horror film. Princeton University Press, 1993.

CREED, B. The monstrous-feminine: film, feminism, psychoanalysis. New York, Routledge, 1993.

GREVEN, D. Representations of femininity in American genre cinema: the woman's film, film noir and modern horror. New York: Palgrave Macmillan, 2011.

KAPLAN, E. A. A mulher e o cinema: os dois lados da câmera. Rio de Janeiro: Rocco, 1993.

KRISTEVA, J. Powers of horror: an essay on abjection. New York: Columbia University Press, 1982.

MULVEY, L. "Prazer visual e cinema narrativo". In: XAVIER, I. A experiência do cinema. Rio de Janeiro: Edições, Graal, 1983.

PARKER, L. "A woman directed the scariest horror movie of the year, maybe of the decade". The Cut. Dec, 05, 2014. Disponível em: http://nymag.com/ thecut/2014/12/meet-jennifer-kent-director-of-the-babadook.html

PEÑUELA CAÑIZAL, E. "A intertextualidade conotada". In: Revista Significação, São Paulo, n. 9, p. 63-76, 1990. 
PITRE, J. "Mama who bore me: on motherhood, horror, and Jennifer Kent's 'The Babadook'". Movie Mezzazine. Nov, 26, 2014. Disponível em: http:// moviemezzanine.com/mama-who-bore-me-on-motherhood-horror-andjennifer-kents-the-babadook/

POE, E. A. "A Filosofia da Composição". Poemas e Ensaios. Trad. Oscar Mendes e Milton Amado. São Paulo: Globo, 1999. 3. ed. revista.

ROLLINS, J. The Babadook: don't let it in. CutPrintFilm. Nov, 26, 2014. Disponível em: http://www.cutprintfilm.com/reviews/babadook/

WILLIAMS, L. "When the Woman Looks". In: GRANT, Barry Keith (Ed). The dread of difference: gender and the horror film. Austin, University of Texas Press, 1996: 15-34.

WOOD, R. "The American Nightmare: Horror in the 70's". In: WOOD, R.; LIPP, R. The american nightmare: essays on the horror film. University of Michigan Press, 1979, p. 25-32.

\section{Principais referências filmográficas:}

MONSTER, Jennifer Kent, Australia, 2005, P\&B, 9 min.

THE BABADOOK, Jennifer Kent, Australia, 2014, Colorido, 93 min.

VINCENT, Tim Burton, EUA, 1982, P\&B, 5 min. 